\title{
解析测量新技术在矿山测量中的运用
}

周国彪

湖北省地质局第四地质大队

DOI:10.32629/gmsm.v2i5.309

[摘 要] 矿山测量在矿山的生产当中是一项基础性的工作,测绘新技术的应用,使矿山的测量工作发生根本性变化。随着计算 机应用、卫星技术、电子技术的发展, 测绘仪器发挥了巨大的作用, 相关的技术手段也有了很大的提高, 形成了现在测绘仪器及 测绘技术的新体系。该文首先分析了矿山测量的重要性,其次主要介绍了几种矿山测量的新技术,并探讨其在矿山测量中的使 用,为矿山更精确高效的测量提供技术支撑,为我国的矿山测量发展奠定扎实的基础。

[关键词] 测量新技术; 矿山测量; 运用

随着测绘科学技术的不断发展, 以计算机技术为核心的 数字测量技术取得了迅猛的发展, 以数字测绘、全球定位系 统、遥感和地理信息系统为代表的测绘新技术体系已经建立, 新型测绘仪器迅速出现与普及, 使矿山测量从理论到实践发 生了根本性变化。

\section{1 矿山测量的重要性}

在我国, 经济社会高速发展, 对矿产资源的需要也日渐 增加, 但是开发矿产资源, 必须以可持续开发为主要发展原 则, 科学合理地运用我国有限的矿产资源。这就需要我们对 矿山进行有效的管理, 而对矿产资源进行寻找和测量时, 为 企业提供准确地参考数据, 为矿产资源的安全开发和开采提 供有力的数据支持。我国大部分矿山的地理环境错综复杂, 受地理环境的影响及气候环境的限制, 给矿山测量的工作造 成极大的影响, 也为矿山测量工作者带来了工作难度, 急需 将现代化的测量仪器应用到矿山测量工作当中。精确的矿山 测量工作不仅能为企业提供及时、准确的分析数据, 从而准 确地确定矿山开采的深度和准确地理位置, 还能确保矿石的 开采率, 减少在矿产资源开采过程中的经济损失。

\section{2 矿山测量新技术的运用}

2.13 S技术在矿山资源中的运用

3S技术主要由GPS (全球定位系统)、RS (空间遥感技术)、 GIS (地理信息技术) 3 个技术构成, 是未来测量工作中发展必 备的基本技术。

\subsubsection{GPS在矿山测量中的运用}

GPS由于其精度高, 功能齐全, 所以在大地测量、工程测 量以及地质灾害中运用较为广泛, 在矿山测量中也起到较 为重要的作用。GPS技术的应用主要是根据国家或者区域所 使用的三维国家大地测量GPS控制网, 充分利用GPS控制网 能够实现国家大地坐标系和世界的大地坐标的参数转换, 对地理学与空间科学的研究有很大的帮助, 特别是矿山测 量方面。GPS-RTK技术和RTK技术具有较高的自动化、集成 化程度、较强的测绘功能、定位精确、操作简便等诸多的 优势。因此, GPS技术与RTK技术融为一体, 可以达到矿山中 多比例尺的测量要求, 有较高的精度和丰富的数据, 可提供
测量人员分析, 在很大程度上提高了矿山测量的工作效率。

2.1.2 RS技术在矿山测量中的运用

遥感技术最大的优点就是在测量时可以不受地形地貌 的限制, 而且测量的范围比传统的方法较大, 能够收集到大 量的信息, 因此在矿山测量中, 遥感技术是十分重要的。

遥感技术能对矿山的地形图开展测绘工作, 对矿山周围 的自然环境、土地资源、地质地貌等都能使用遥感技术来实 现, 同时, 利用遥感影像对矿山资源进行测量, 对于矿产资源 的发展起到了重要作用。利用成孔径雷达干涉测量技术被广 泛运用到矿产资源测量中, 成孔径雷达主要是利用雷达信号 的相位信息来收集地球表面的三维信息, 可以及时准确地对 地面点高程的变动进行观测, 能够充分了解地表信息的变动, 从而有效监测地表沉降情况, 同时, 还可以获悉导致地表形 变的主要因素, 向矿山测量工作人员提供了真实可靠的地表 信息。

\subsection{GIS在矿山测量中的应用}

在矿山中矿山测量工作人应积极创建三维矿山模型, 并把它应用到找矿当中去, 这样可以确切地把握明确的矿 体的具体位置。对各种矿石的类型进行全面了解, 还可对各 类矿石的分布状况进行全面了解, 从而保证矿石施工的和 开采的安全和效率。矿山测量的工作人员根据地理信息系 统构建的多元数据找矿模型, 能够根据数据不同的空间属 性准确地寻找到矿石, 从而促进矿上测量工作正常、有序的 进行。建立矿山的地理信息管理系统是整个矿山管理工作 的重要内容, 当前管理系统涉及的方面比较广, 对信息的准 确性和实时性的要求也比较高, 利用这个系统不仅能够有 效地提高矿山管理的各个环节, 还能使地理信息系统的性 能得得到充分的发挥。

\section{2全站仪在矿山测量中的运用}

在矿山的测量中, 运用最广泛的要数全站仪了, 作为光 学技术与电子信息技术的结合一种光电测量仪器, 不仅具有 电子经纬仪的优点, 同时还具备了测距仪的优点, 全站仪正 在向智能化和全面化发展, 全站仪的作用主要是与现代化信 息技术作为支撑, 构建矿山的三维立体数据库, 从而实现对 
实时数据的自动采集、传递、分析的自动化矿山测量的数据 系统, 这种方式取代了传统的、陈旧的手工输入和繁琐计算 的工作, 提高了整个矿山作业的工作效率, 节约了矿山的人 力资源成本。此外, 在矿山的地表移动情况、施工状况、土 地实际情况等等都能够运用全站仪进行全面的检测。全站仪 的测量效果是显而易见的, 加上自身的便捷性, 受到了矿山 测量人员的喜爱。

2. 3惯性测量系统在矿山测量中的运用

惯性测量实际上就是一种定位导航技术的使用, 在具 体的矿山测量过程中由于其自主式、全天候、机动灵活的 特点, 给矿山测量提供了一种新型的测量方式。惯性测量主 要的工作原理就是根据收集高程、方位角、垂线偏差和重 力异常的数据来进行综合分析的一种技术系统。该系统的 主要优点是能够弥补GIS技术的不足, 从而更精确的对矿山 进行测量, 保证测量工作的有序高效进行, 减少测量过程中 的误差。

\section{4 三维激光扫描技术在矿山测量中的运用}

三维激光技术原理主要是根据高密度点状的数据通过 对体积的计算, 对实景进行复制的一种新型技术。这种技术 最大的优点在于其速度快, 成本低、进度高、安全系数较高、 数据点的密集程度也较大, 管理起来比较方便。因此, 三维激 光技术被广泛地运用到矿山测量当中。但是目前我国的三维 激光技术还处于起步阶段, 在实际的测量过程中, 可能会出 现对地形依赖性大, 对环境的适应性差等等问题, 还需要我
们不断地探索和创新。

2.5 其他测绘新技术在矿山测量中的应用

矿山的测量方法很多, 除了上文提到的几种主要的方法 之外, 还有陀螺经纬仪、激光指向仪、数字式水准仪等相关 的仪器的运用, 通过使用仪器来对矿山的基本情况进行全面 的了解, 并在使用过程中不断地创新和改良, 建立更加精确、 高效、便捷的矿山测量系统。

\section{3 结束语}

随着社会发展的需要, 人们对矿产资源的需求也越来越 高, 精确、快速地获取矿山测量的数据成为矿山测量的主要 内容。测绘技术作为一门交叉性学科, 依托计算机技术、卫 星技术、电子技术、光学技术等的发展而进步, 近年来形成 了现代测绘仪器及技术的新体系, 并且广泛的应用于矿山测 量中。测绘新技术具有测量精确度高、工作效率快、操作便 捷性等优势, 在矿山测量中应用测绘新技术, 可大大提高矿 山开采的效率和规范化。因此, 为了更好地发挥测绘新技术 在矿山测量中的作用。

\section{[参考文献]}

[1]胡滨.测绘新技术在矿山测量中的应用与发展分析 [J].山东煤炭科技,2015(10):130-132.

[2]邱崇德.测量新技术在矿山测量中的应用 [J].河南科 技,2013(12):56-57.

[3]任海青.测绘新技术在矿山测量中的应用及发展 [J]. 能源与节能,2016(08):115-116. 